\title{
Family economic vulnerability \& the Great Recession: an analysis of the first two waves of the Growing Up in Ireland study
}

\author{
Dorothy Watson \\ Christopher T. Whelan
}

christopher.whelan@ucd.ie

\section{Bertrand Maître James Williams}

(Received November 2014

\author{
Economic and Social Research Institute, Dublin and Trinity College, Dublin \\ University College Dublin
}

Economic and Social Research Institute, Dublin and Trinity College, Dublin

Economic and Social Research Institute, Dublin and Trinity College, Dublin

Revised January 2015)

http://dx.doi.org/10.14301/Ilcs.v6i3.331

\section{Abstract}

In this paper we make use of the first and second waves of the 2008 and 1998 cohorts of the Growing Up in Ireland study, to develop a multidimensional and dynamic approach to understanding the impact on families and children in Ireland of the Great Recession. Economic vulnerability is operationalised as involving a distinctive risk profile in relation to relative income, household joblessness and economic stress. We find that the recession was associated with a significant increase in levels of economic vulnerability and changing risk profiles involving a more prominent role for economic stress for both the 2008 and 1998 cohorts. The factors affecting vulnerability outcomes were broadly similar for both cohorts. Persistent economic vulnerability was significantly associated with lone parenthood, particularly for those with more than one child, lower levels of primary care giver (PCG) education and, to a lesser extent, younger age of PCG at child's birth, number of children and a parent leaving or dying. Similar factors were associated with transient vulnerability in the first wave but the magnitude of the effects was significantly weaker particularly in relation to lone parenthood and level of education of the PCG. For entry into vulnerability the impact of these factors was again substantially weaker than for persistent and transient vulnerability indicating a significantly greater degree of socioeconomic heterogeneity among the group that became vulnerable during the recession. The findings raise policy and political problems that go beyond those associated with catering for groups that have tended to be characterized by high dependence on social welfare.

Keywords: Economic vulnerability, life course, social class, economic class 


\section{Introduction}

Ireland has seen quite remarkable macroeconomic fluctuations over the past two decades, with the fastest economic growth rate among the countries of the Organisation for Economic Co-operation and Development (OECD) during the so-called 'Celtic Tiger' boom being followed by a recession which had a more negative impact on national output in Ireland than in any other OECD country. The decade of exceptionally rapid growth from the mid-1990s saw the numbers employed expand dramatically and unemployment reduced to $4 \%$, but was characterized by an unsustainable credit-fuelled expansion in the construction sector and an unprecedented property price boom. From 2008 onwards, the country faced the bursting of the property bubble, a collapse of property-related tax revenues, falling asset values, a major banking crisis and a ballooning fiscal deficit. This toxic combination meant that by late 2010, despite substantial increases in taxation and expenditure cuts, the Irish government had to avail itself of a 'bail-out' from the Troika (Whelan, 2010). The impact of the recession involved a decline of 13\% in GDP between 2008 and 2011 and a rise in unemployment from $4 \%$ to $14 \%$ between 2007 and 2011 (Callan, Nolan, Keane, Savage \& Walsh, 2013). In the context of a sharp decline in real household incomes and associated poverty thresholds, at-risk of poverty rates based on $60 \%$ of median income remained relatively stable over time. However, sharp increases were observed in levels of material deprivation and economic stress. Throughout the period 2004-2011 at-risk of poverty rates based on $60 \%$ of median income and material deprivation rates were significantly higher for children than for the remainder of the population. Both rates were higher than for most of the EU15 countries (Watson, Maître \& Whelan, 2012). ${ }^{1}$

The research reported in this paper draws on data from the Growing Up in Ireland (GUI) Survey that were collected between 2007 and 2011. Data for two cohorts of children are used, one born in 1998 (the 1998 cohort) and one born in 2008 (the 2008 cohort). The availability of data for two waves for each cohort allows us to compare the pre and post-recession situations of families with infant children (age nine months and three years) and children in middle childhood (age nine and 13 years). Our analysis takes advantage of the longitudinal nature of the GUI survey and adopts a multidimensional perspective. It has been wellestablished, for instance, that the groups identified on the basis of low income alone differ from those found to experience multiple deprivation in terms of factors such as employment status, stage of the life course, housing tenure and urban-rural location (Nolan \& Whelan, 1996). Thus, in line with emerging trends on the literature, our approach is both multidimensional and dynamic (Nolan \& Whelan, 2007,2010 ). A great deal of debate has taken place regarding the range of dimensions which should be incorporated in measures of childhood poverty or deprivation (Tomlinson, Walker \& Williams, 2009). A crucial factor here is the position one adopts regarding the relative importance of description versus identifying causal processes. Here, rather than attempting to capture the full range of deprivations experienced by children, we focus on a multidimensional but restricted conception of economic vulnerability based on low income, household joblessness and subjective economic stress. We then proceed to explore the socioeconomic factors which contribute to changing patterns of exposure to such vulnerability and their consequences. This broader measure of economic vulnerability offers a number of advantages as an indicator of longer term command over resources (Whelan \& Maître, 2005).

Our research is intended to provide a contribution to the literature on the socioeconomic distribution of childhood poverty and its consequences. A good deal of the evidence relating to the extent and consequences of persistent poverty in childhood is drawn from the United States where welfare structures and child supports are distinctive (Duncan, Magnuson, Kalil \& ZiolGuest, 2012). However, as Mood and Jonsson (2014) note, increasing interest in child poverty and deprivation is related to United Nations' (UN) demands that, having ratified the Child Convention, countries monitor trends in the living conditions of children. This, as they note, has led to the development of a range of relevant welfare indices with material living conditions featuring as a central indicator of children's well-being (Bradshaw, Hoelscher \& Richardson, 2006; Bradshaw \& Richardson, 2009; UNICEF, 2007).

\section{The Growing Up in Ireland (GUI) data}

The GUI survey is a national longitudinal study of children. It tracks the development and wellbeing of 
two nationally representative cohorts of children: the 1998 cohort and the 2008 cohort. The samples were strict probability samples. The 1998 cohort of children was selected following clustering at the level of the school, while the 2008 cohort was a random sample selected from the Child Benefit records with the assistance of the Department of Social Protection. Interviews were conducted via Computer-Assisted Personal Interview (CAPI) with the primary care-giver (PCG, usually the mother), the resident secondary care-giver (SCG, usually the father), the teachers of the 1998 cohort of children at wave one and with the 1998 cohort children themselves. In the present analysis we rely on data provided by the PCG.

In this paper, data from the first two waves of both cohorts are used, when the children in the 2008 Cohort were nine months and subsequently three years old and those in the 1998 Cohort were nine and subsequently 13 years of age. The samples in the study were reweighted or statistically adjusted to ensure that they were nationally representative of the age groups in question, both cross-sectionally and longitudinally. ${ }^{2}$ The present analysis includes the 9,793 families who responded in both waves of the 2008 cohort and the 7,423 families who responded in both waves for the 1998 cohort. The large sample sizes, the probability samples and the calibration to ensure representativeness mean that the results can be generalised to the population of children in both cohorts.

The timing of the GUI surveys in relation to the onset of 'The Great Recession' is important. The first wave of the 1998 cohort was conducted with the families of the nine-year olds between August 2007 and June 2008, slightly before the major shocks of the recession later that year. The second wave, when the children were aged 13, took place between August 2011 and March 2012. This corresponded to the deepest point of the recession, before any growth in employment was evident. The first wave of the 2008 cohort, when the children were aged nine months, occurred between September 2008 and March 2009 right at the start of the recession when unemployment was rising most sharply. The second wave, when the children were three years old, was from December 2010 to July 2011. At this stage, unemployment was still increasing and GNP was still falling but at a much slower rate.
Given the timing of the fieldwork, we would expect that the families of the 2008 cohort would already be beginning to experience the effects in terms of unemployment or concerns about employment loss in the first wave. For this reason, we might expect that the impact of the recession would be seen most clearly in the 1998 cohort since the first wave interviewing was substantially completed before the very steep rise in unemployment in the fourth quarter of 2008.

\section{Identifying economically vulnerable groups}

As knowledge of the limitations of relying solely on income to measure poverty and social exclusion has become more widespread, attention has been increasingly focused on multi-dimensional approaches (Grusky \& Weeden, 2007, Nolan \& Whelan, 2007, 2010). In addition to being concerned with multidimensionality, advocates of the social exclusion perspective have sought to distinguish it from the conventional income approach through its emphasis on dynamics - the manner in which processes unfold over time. Such concerns have led to the emergence, from a number of sources, of a focus on what has been termed 'vulnerability'. This involves a shift of focus from current deprivation to insecurity and exposure to risk and shock. The International Monetary Fund (IMF) (2003), the UN (2003) and the World Bank (2000) have developed a range of approaches to measuring vulnerability at the macro level. The World Bank (2000) sees vulnerability as reflecting the risk of experiencing an episode of poverty over time but also a heightened probability of being exposed to a range of disadvantages. Hanappi, Bernardi and Spini (2015), in a systematic review of social science literature using the concept of vulnerability, argue that 'vulnerability is a major concept for interdisciplinary research and potential theory development'. The authors suggest that vulnerability may remain latent until individuals or groups are challenged by critical events or the depletion of limited resources. ${ }^{3}$

Our objective in this paper is to focus at a micro level in order to identify families who are vulnerable to economic exclusion in the sense of being distinctive in their risk of falling below a critical resource level, living in a household characterised by a high level of joblessness and experiencing subjective economic stress. In other research, using 
the Survey of Income and Living (SILC) data, economic vulnerability has been measured using indicators of income poverty status, material deprivation and economic stress (Whelan \& Maître, $2005,2010,2014)$. Our choice of indicators in the present study is influenced both by substantive considerations and the quality of the data available in the GUI surveys. Details of the three components of economic vulnerability are shown in figure 1 . We use a similar indicator of economic stress but a slightly different measure of income level and we substitute household joblessness for material deprivation. A comparison of material deprivation levels for comparable families in GUI and SILC showed that levels of deprivation in the former were substantially below those reported in the latter. This was despite the fact that no such differences were observed in relation to the distribution of income and key socioeconomic factors that have been shown to be associated with levels of deprivation. One possibility is that social desirability considerations may have led parents to be reluctant to report material deprivation in the context of a survey focused on children. In any event, the unrealistically low levels of such deprivation in the GUI survey in comparison with comparable groups in the SILC data, led us to exclude this dimension, which has been employed in previous analyses of economic vulnerability (Whelan \& Maître, 2010), and instead focus on household joblessness.

Income level refers to the quartile of equivalised household income. Equivalised income refers to total household income from all sources and all household members, net of taxes and social contributions, and adjusted for household size and composition by dividing by an equivalence scale. ${ }^{4}$

Income is measured by a single item answered by the PCG in GUI and is, therefore, not measured with as much precision as in SILC which is specifically designed for the purpose of collecting detailed income information. ${ }^{5}$ Consequently, in what follows we focus on income quartiles rather than seeking to estimate numbers below conventional income poverty lines.

Economic stress is measured by a single item which has been used extensively in Irish surveys to capture 'difficulties in making ends meet'. Household joblessness is defined using the European Commission concept of 'very low work intensity', as described in figure 1.

Figure 1: The components of economic vulnerability

\begin{tabular}{ll}
\hline Variable & Description \\
\hline Income level & $\begin{array}{l}\text { The income quartile of the household calculated separately for each cohort } \\
\text { in each time period. One quarter of each cohort in wave one and in wave } \\
\text { two is found in each quartile. }\end{array}$ \\
\hline Economic stress & Whether the family has 'great difficulty' or 'difficulty' in making ends meet. \\
\hline $\begin{array}{l}\text { Household } \\
\text { joblessness ('very }\end{array}$ & $\begin{array}{l}\text { The working-age adults in the household are currently in employment for } \\
\text { less than one fifth of the available hours. Working-age adults are aged 18 to } \\
\text { low work }\end{array}$ \\
$\begin{array}{l}\text { 59, excluding full-time students under age 25. The percentage of available } \\
\text { time worked is calculated as a percentage of 35 hours, which is regarded as } \\
\text { full-time for this purpose. This percentage is capped at 100. }\end{array}$ \\
$\begin{array}{l}\text { Note: hours worked are available for the primary and secondary care-givers } \\
\text { only. For other adults of working age, we only know whether or not they are } \\
\text { in employment. In calculating work intensity, we assume the work of any } \\
\text { other adults is full-time. }\end{array}$ \\
\hline
\end{tabular}

The approach we adopt in analysing economic vulnerability involves an analysis of manifest indicators in order to identify underlying or latent vulnerability. We achieve this objective by the application of latent class analysis, which can be used as a tool to gain deeper understanding of the observed relationships between categorical indicators. It can be thought of as a log-linear model where there are more dimensions in the estimated table than in the observed table. Such models generate tables of expected frequencies that can be compared to the observed frequencies using goodness of fit tests. The 
basic idea underlying such analysis is long established and very simple (Lazarsfeld, 1950). The associations between a set of categorical variables, regarded as indicators of an unobserved typology, are accounted for by membership of a small number of latent classes. As Moisio (2004) notes, implicit in the notion of multidimensional measurement of social exclusion is the assumption that there is no one 'true' indicator of the underlying concept. Instead, we have a sample of indicators that tap different aspects of a complex phenomenon. Latent class analysis assumes that each individual is a member of one and only one of $\mathrm{N}$ latent classes and that, conditional on latent class membership, the manifest variables are mutually independent of each other. Conditional independence is a version of the familiar idea that the correlation between two variables may be a result of their common dependence on a third variable (McCutheon \& Mills, 1998). In estimating latent class models the logic is identical but the explanatory variable is unobserved and must be identified statistically. The axiom of local independence can be seen as the defining characteristic of latent class analysis. It assumes causality running from the latent variable to the manifest indicators.

The three measured characteristics of the families shown in figure 1 yield a 16 -cell table $(4 \times 2 \times 2)$ relating to multidimensional profiles of economic exclusion. Such a profile can be established for each of the four groups we consider:

- The 2008 cohort at nine months

- The 2008 cohort at three years

- The 1998 cohort at nine years

- The 1998 cohort at 13 years
Taking into account both the range of indicators and the number of groups produces a 64 cell table. Our objective is to develop a parsimonious latent class model of the underlying processes producing an allocation of individuals to the cells of this table that generates a set of expected values that provide a satisfactory fit.

Since our objective is to identify an overall economically vulnerable class that can be contrasted with the remainder of the population, we develop models with two latent classes ${ }^{6}$. For each model we report the likelihood ratio chisquare test $\left(\mathrm{G}^{2}\right)$ and the percentage of cases misclassified. The findings relating to a number of models are set out in table 1. The first model, which we use as a benchmark for the performance of the remaining models, allows for an association between the manifest indicators of economic vulnerability and cohort and but assumes no association between the vulnerability indicators. Not surprisingly, this model provides a poor fit to the data and misclassifies $16.6 \%$ of the cases.

A fully homogeneous latent class model reduces the $\mathrm{G}^{2}$ for the conditional independence model by $76.8 \%$ but misclassifies $6.7 \%$ of cases. The model that allows the size of the vulnerable class to vary by cohort and time reduces the $\mathrm{G}^{2}$ by $80.3 \%$ and misclassifies $5.9 \%$ of cases. Finally the fully heterogeneous model, which allows both the size and the profile of the vulnerable class to vary across combinations of cohorts and observation periods, reduces the conditional independence $\mathrm{G}^{2}$ by $99.4 \%$ and misclassifies $2.8 \%$ of cases.

Table 1: Latent class model fit statistics for GUI data

\begin{tabular}{|c|c|c|c|c|}
\hline & $\mathrm{G}^{2}$ & $\begin{array}{l}\text { Degrees of } \\
\text { freedom }\end{array}$ & $\begin{array}{l}\text { Reduction in } \\
\text { independence } \mathrm{G}^{2}\end{array}$ & $\begin{array}{l}\% \text { of cases } \\
\text { misclassified }\end{array}$ \\
\hline \multicolumn{5}{|l|}{ Models } \\
\hline 1. Conditional independence & $7,647.5$ & 45 & & 16.6 \\
\hline 2. Fully homogenous & $1,775.3$ & 49 & 76.8 & 6.7 \\
\hline 3. Heterogeneous on size by cohort \& time & $1,508.0$ & 46 & 80.3 & 5.9 \\
\hline 4. Fully heterogeneous & 480.3 & 16 & 99.4 & 2.8 \\
\hline
\end{tabular}

Source: GUI Longitudinal ' 98 Cohort and '08 Cohort datasets, analysis by authors. 
A satisfactory fit requires that we take into account differences in the size of the vulnerable class and vulnerability profiles relating to both cohort and period and the manner in which they interact. Having done so, the fully heterogeneous model provides a reasonably satisfactory account of the observed patterns of multidimensional economic vulnerability across cohort and time.

\section{Levels and profiles of economic vulnerability by age group and cohort}

In table 2 we show the size of the economically vulnerable class by cohort and time period and the profile of the vulnerable and non-vulnerable groups in terms of the three indicators. The sizes of the vulnerable classes are based on assigning individuals to the class in which they have the highest probability of being located. ${ }^{7}$ The table also shows the percentage of cases that would be misclassified under the model assumptions of zero association between the manifest indicators within latent classes. The figure ranges from $2 \%$ to $4.5 \%$, indicating a generally acceptable model fit.

Focusing first on latent class size we find that for the 2008 cohort the observed level of economic vulnerability was $19 \%$ in wave one and rose to $25 \%$ in wave two. For the older 1998 cohort the level was substantially lower in the first period of observation at $15 \%$. However, by the second period it rose sharply to $25 \%$. The difference in fieldwork timing, noted earlier, is important in accounting, at least in part, for the higher level of economic vulnerability among the 2008 cohort in the first wave and the sharper increases between waves for the 1998 cohort.

The conditional probabilities show, for each combination of period and cohort, the contrast between vulnerable and non-vulnerable latent classes in terms of their risk of being found in the most disadvantaged categories of each of the manifest indicators. Focusing on the younger 2008 cohort, we find that while $63 \%$ of the vulnerable class are found in the bottom quartile, this figure falls to $10 \%$ for the non-vulnerable class. The respective figures for the third and fourth deciles combined are $3 \%(2 \%+1 \%)$ and $68 \%(34 \%+34 \%)$. In relation to economic stress, $36 \%$ of the vulnerable class were above the relevant threshold compared to $4 \%$ of the non-vulnerable. Finally, $48 \%$ of the vulnerable class fulfilled the joblessness criterion compared to $1 \%$ of the non-vulnerable class. By the second time period when the children were three years old, a relatively similar situation existed in relation to the numbers in the bottom quartile, with respective figures of $62 \%$ and $9 \%$, and in the third and fourth quartiles combined, with figures of $4 \%(4 \%+0 \%)$ for the vulnerable class and $70 \%(34 \%+36 \%)$ for the non-vulnerable class. However, economic stress levels rose among both vulnerable and non-vulnerable classes producing respective levels of $47 \%$ and $10 \%$, so that the relative disadvantage of the vulnerable class narrowed while the absolute difference showed a modest increase. Finally, the level of joblessness showed little change for the non-vulnerable class but rose to $58 \%$ for the vulnerable class. So as the size of the vulnerable class increased, striking differences in risk profiles persisted but the impact of the recession was uneven across the component indicators.

Turning our attention to the older 1998 cohort, we find that in wave one the number found in the bottom income quartile is higher than for the younger 2008 cohort at $15 \%$ but once again is substantially higher for the vulnerable group at $69 \%$. As in the 2008 cohort, stress levels were substantially higher for the vulnerable than the non-vulnerable group with respective figures of $31 \%$ and $2 \%$. The contrast in terms of joblessness was even sharper than in the case of the younger cohort with a figure of $58 \%$ for the vulnerable class and $1 \%$ for the non-vulnerable class. As the size of the vulnerable class rose significantly, differentiation in terms of income quartiles became less sharp. Thus the number in the vulnerable class in the bottom quartile declined from $69 \%$ to $49 \%$ while the number in the second quartile rose from $26 \%$ to $42 \%$ and in the top half rose from $4 \%(4 \%+$ $0 \%)$ to $8 \%(7 \%+1 \%)$. In relation to economic stress, we observe increases that are somewhat larger than in the case of the 2008 cohort resulting in levels of $55 \%$ and $10 \%$ for the vulnerable and nonvulnerable classes, respectively. In contrast, as with the income quartiles, differentiation in relation to household joblessness narrowed slightly with respective figures of $50 \%$ and $1 \%$ cent for the vulnerable and non-vulnerable clusters. 
Table 2: Latent class size and profiles by cohort

\begin{tabular}{|c|c|c|c|c|c|c|c|c|}
\hline & \multicolumn{2}{|c|}{9 months old } & \multicolumn{2}{|c|}{3 years old } & \multicolumn{2}{|c|}{9 years old } & \multicolumn{2}{|c|}{13 years old } \\
\hline \% Vulnerable & \multicolumn{2}{|c|}{18.8} & \multicolumn{2}{|c|}{25.4} & \multicolumn{2}{|c|}{14.7} & \multicolumn{2}{|c|}{24.9} \\
\hline$\%$ of cases misclassified & \multicolumn{2}{|c|}{2.45} & \multicolumn{2}{|c|}{4.51} & \multicolumn{2}{|c|}{2.04} & \multicolumn{2}{|c|}{2.21} \\
\hline \multirow[t]{2}{*}{ Economically vulnerable } & $\begin{array}{c}\text { Not } \\
\text { vulner- } \\
\text { able }\end{array}$ & $\begin{array}{l}\text { Vulner- } \\
\text { able }\end{array}$ & $\begin{array}{c}\text { Not } \\
\text { vulner- } \\
\text { able }\end{array}$ & $\begin{array}{l}\text { Vulner- } \\
\text { able }\end{array}$ & $\begin{array}{c}\text { Not } \\
\text { vulner- } \\
\text { able }\end{array}$ & $\begin{array}{l}\text { Vulner- } \\
\text { able }\end{array}$ & $\begin{array}{c}\text { Not } \\
\text { vulner- } \\
\text { able }\end{array}$ & $\begin{array}{l}\text { Vulner- } \\
\text { able }\end{array}$ \\
\hline & \multicolumn{2}{|c|}{$\begin{array}{l}\text { Conditional } \\
\text { probabilities }\end{array}$} & \multicolumn{2}{|c|}{$\begin{array}{l}\text { Conditional } \\
\text { probabilities }\end{array}$} & \multicolumn{2}{|c|}{$\begin{array}{l}\text { Conditional } \\
\text { probabilities }\end{array}$} & \multicolumn{2}{|c|}{$\begin{array}{l}\text { Conditional } \\
\text { probabilities }\end{array}$} \\
\hline \multicolumn{9}{|l|}{ Income quartile } \\
\hline 1 & $10 \%$ & $63 \%$ & $9 \%$ & $62 \%$ & $15 \%$ & $69 \%$ & $14 \%$ & $49 \%$ \\
\hline 2 & $22 \%$ & $34 \%$ & $21 \%$ & $34 \%$ & $25 \%$ & $26 \%$ & $18 \%$ & $42 \%$ \\
\hline 3 & $34 \%$ & $2 \%$ & $34 \%$ & $4 \%$ & $30 \%$ & $4 \%$ & $33 \%$ & $7 \%$ \\
\hline 4 & $34 \%$ & $1 \%$ & $36 \%$ & $0 \%$ & $31 \%$ & $0 \%$ & $35 \%$ & $1 \%$ \\
\hline Economic stress & $4 \%$ & $36 \%$ & $10 \%$ & $47 \%$ & $2 \%$ & $31 \%$ & $10 \%$ & $55 \%$ \\
\hline Joblessness & $1 \%$ & $48 \%$ & $0 \%$ & $58 \%$ & $1 \%$ & $58 \%$ & $1 \%$ & $50 \%$ \\
\hline Number of cases & \multicolumn{2}{|c|}{9679} & \multicolumn{2}{|c|}{9679} & \multicolumn{2}{|c|}{7408} & \multicolumn{2}{|c|}{7408} \\
\hline
\end{tabular}

Source: GUI Longitudinal 1998 Cohort and 2008 Cohort datasets, analysis by authors.

Thus the size of the vulnerable group increased for both cohorts but more so for the older 1998 one. Members of the vulnerable group remained sharply differentiated from the non-vulnerable but trends varied across the component items. Economic stress levels increased for both vulnerable and non-vulnerable groups for both cohorts. In contrast joblessness remained minimal for the non-vulnerable in both cohorts, increased for the vulnerable 2008 group but declined for the vulnerable cluster in the 1998 cohort. This latter finding is consistent with the fact that for the 13year old group, vulnerability was significantly more widely distributed across the income distribution as the impact of the Great Recession led to a more pervasive distribution of economic stress. This finding is consistent with analysis of the impact of the Great Recession on adult economic vulnerability levels and profiles employing EU-SILC data (Whelan \& Maître, 2014).

\section{Economic vulnerability patterns by family characteristics}

At this point we examine the extent to which there was change or stability over time in the economic vulnerability status of families. As noted above, individuals are allocated to the vulnerable or non-vulnerable class on the basis of the modal assignment rule with each observation in a cell being assigned to the cluster with the largest probability. Employing this approach in figure 2, we show the proportion of children in the two cohorts who are found in each of the four economic vulnerability classes: economically vulnerable in neither period; vulnerable in wave one only; vulnerable in wave two only and vulnerable in both waves. 
Figure 2: Economic vulnerability of the two cohorts

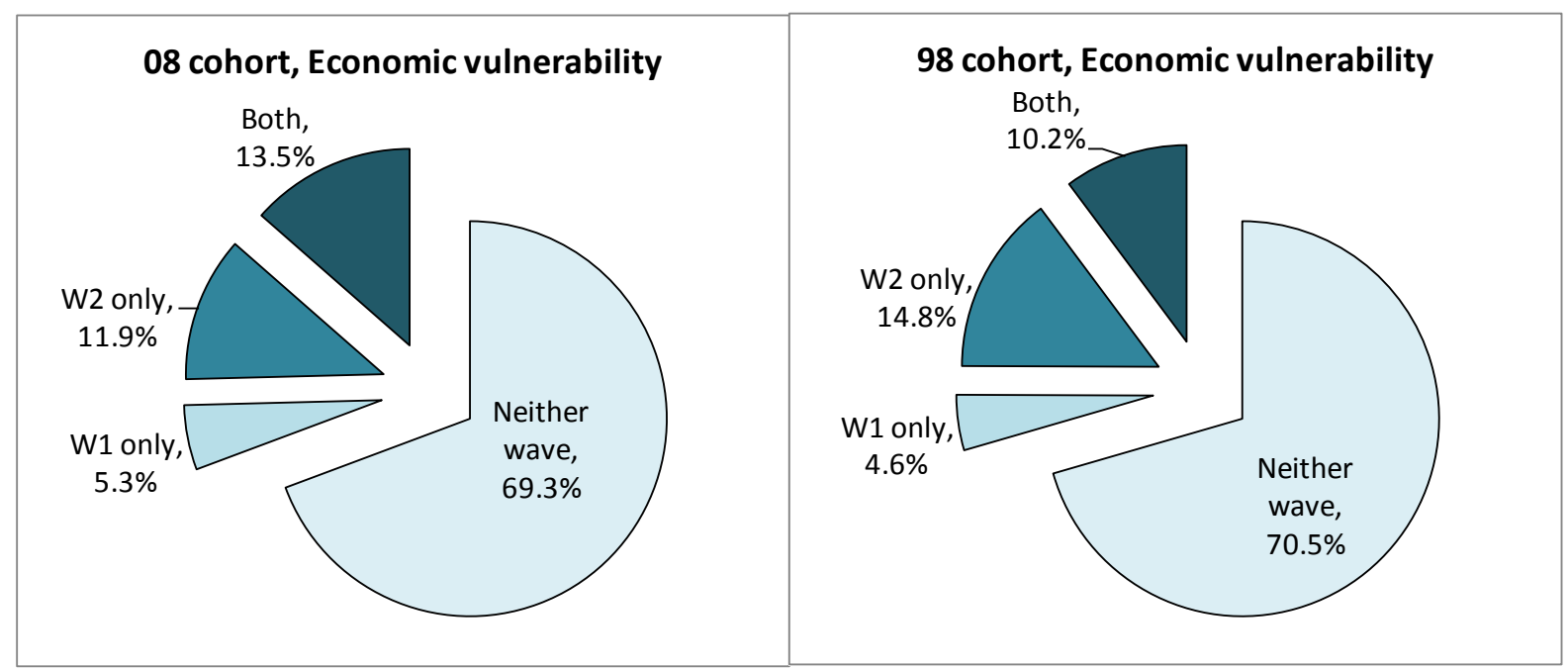

Source: GUI Longitudinal 1998 Cohort and 2008 Cohort datasets, analysis by authors. The relative risk of being vulnerable in wave 2 only or in both waves is significantly higher for the 1998 cohort.

The proportion of children who were economically vulnerable in neither period is very similar for the younger and older cohorts at about $70 \%$. The proportion vulnerable in wave two is also very similar at about $25 \%$. Among the younger cohort, $14 \%$ were economically vulnerable in both periods compared to $10 \%$ of the older cohort.

Inevitably, given the recession, most of the change in vulnerability status involved movements into economic vulnerability. About $12 \%$ of the younger cohort and $15 \%$ of the older cohort experienced this transition. Roughly $5 \%$ of children in both cohorts experienced movement in the opposite direction.

In table 3 we provide a description of patterns of vulnerability for the combined 2008 and 1998 cohorts by a range of family characteristics that previous research suggests are likely to be associated with vulnerability (e.g. Fahey, Keilthy \& Polek, 2012; Watson, Maître \& Whelan, 2012). These include household type, educational level and age at birth of the PCG, cohabitation and changes in household status relating to parents and number of children. We focus first on the likelihood of being vulnerable in both waves. The highest expected risk is for lone parents with two children (49\%), followed by lone parents with one child (36\%). It then declines sharply to $9 \%$ for a couple with $3+$ children and $5 \%$ for families with 2 children and $4 \%$ for those with one child. The next most powerful influence was the educational level of the PCG. For lower second level or below, the rate was
$27 \%$. It then fell to $9 \%$ for upper second or lower third level and finally to $2 \%$ for upper third level. Persistent vulnerability was highest among those PCGs who were youngest when the child was born. For those aged less than 25 the rate was $28 \%$ and for those aged between $25-29$ it fell to $15 \%$, For no other group was the risk above $11 \%$. Where a new parent was present in the new wave, $37 \%$ experienced persistent vulnerability, compared to $19 \%$ where a parent had died or left and $11 \%$ where there was no change. Neither cohabitation nor more children in wave two had any effect.

For those experiencing economic vulnerability in wave one only, a similar but much less sharp pattern of social differentiation emerges. The fact that such transient poverty is likely to be affected by a wide variety of relatively specific factors while at the same time a significant degree of social structuring remains evident, is consistent with the likelihood that families who experience economic vulnerability in highly favourable economic circumstances but then manage to exit this state are likely to experience recurring spells of vulnerability. In relation to family type, the highest probability of being vulnerable only in wave one was observed for lone parents with two children with a rate of $15 \%$. This fell to $12 \%$ for their counterparts with one child and to between $3-4 \%$ for the remaining family types. Focusing on age of PCG, the highest rate of between $7-9 \%$ was observed for the under 30 groups before falling to 3-5\% for older groups. For educational level the 
rate declined from $8 \%$ for the least educated group to $3 \%$ for the most educated. Where a new care giver joined by wave 2 the rate was highest at $16 \%$ but a parent dying or leaving had no effect.

Table 3: Observed economic vulnerability pattern by family characteristics

\begin{tabular}{|c|c|c|c|c|c|}
\hline & & W1 only & W2 only & Both & Neither \\
\hline \multirow[t]{5}{*}{ Age of PCG at birth of child } & Under 25 & $9 \%$ & $20 \%$ & $28 \%$ & $43 \%$ \\
\hline & $25-29$ & $7 \%$ & $14 \%$ & $15 \%$ & $64 \%$ \\
\hline & (30-44 ref.) & $4 \%$ & $11 \%$ & $8 \%$ & $78 \%$ \\
\hline & $35-39$ & $3 \%$ & $11 \%$ & $7 \%$ & $78 \%$ \\
\hline & $40+$ & $5 \%$ & $15 \%$ & $11 \%$ & $69 \%$ \\
\hline \multirow[t]{5}{*}{ Household type W1 } & Lone parent, 1 child & $12 \%$ & $13 \%$ & $36 \%$ & $39 \%$ \\
\hline & Lone parent, $2+$ children & $15 \%$ & $12 \%$ & $49 \%$ & $25 \%$ \\
\hline & Couple, one child & $4 \%$ & $10 \%$ & $4 \%$ & $82 \%$ \\
\hline & Couple 2 children & $3 \%$ & $13 \%$ & $5 \%$ & $79 \%$ \\
\hline & Couple, $3+$ children & $3 \%$ & $16 \%$ & $9 \%$ & $72 \%$ \\
\hline \multirow[t]{2}{*}{ Cohabiting W1 } & No & $5 \%$ & $12 \%$ & $12 \%$ & $71 \%$ \\
\hline & Yes & $6 \%$ & $18 \%$ & $12 \%$ & $64 \%$ \\
\hline \multirow[t]{3}{*}{ Change in parent(s) } & No change, same parent(s) & $5 \%$ & $12 \%$ & $11 \%$ & $72 \%$ \\
\hline & New parent & $16 \%$ & $11 \%$ & $37 \%$ & $36 \%$ \\
\hline & One parent died/left & $6 \%$ & $32 \%$ & $19 \%$ & $43 \%$ \\
\hline \multirow[t]{2}{*}{ More children in Wave 2} & No & $5 \%$ & $13 \%$ & $12 \%$ & $69 \%$ \\
\hline & Yes & $3 \%$ & $12 \%$ & $12 \%$ & $73 \%$ \\
\hline \multirow[t]{3}{*}{ PCG Education, W1 } & Low 2nd or less & $8 \%$ & $19 \%$ & $27 \%$ & $46 \%$ \\
\hline & Upper 2nd to lower 3rd & $5 \%$ & $14 \%$ & $9 \%$ & $73 \%$ \\
\hline & Upper 3rd & $3 \%$ & $6 \%$ & $2 \%$ & $89 \%$ \\
\hline
\end{tabular}

Source: GUI Longitudinal 1998 Cohort $(\mathrm{N}=7,423)$ and 2008 Cohort $(\mathrm{N}=9,793)$ datasets, analysis by authors.

For those experiencing vulnerability in wave two only, a rather different pattern of socioeconomic differentiation is observed. Families with the youngest head of households were again at the highest level of risk with a rate of $20 \%$. However, on this occasion the figure for the $40+$ group at $15 \%$ is marginally higher than for the 25-29 group. For the remaining groups the figure falls to $11 \%$. Once again risk is clearly related to education level and ranges from $19 \%$ for the lowest level of qualification to $6 \%$ for the highest. Those families where a parent left or died were sharply differentiated from other families with a risk level of $32 \%$ compared to between 11 and $12 \%$. The loss of a parent is clearly a traumatic event which is associated with persistent vulnerability and entry into vulnerability. The arrival of a new parent has little effect on entry into vulnerability, but is strongly associated with both persistent and transient vulnerability. This may well reflect longer term processes of family instability. In contrast to the earlier findings, the pattern of differentiation by family type is extremely modest with no clear contrast between lone parent families. The highest rate of $16 \%$ is observed for couples with three or more children and the lowest of $10 \%$ for couples with one child. Cohabitation and having more children in wave two had little effect.

The probability of being vulnerable in neither wave obviously follows directly from the outcomes discussed to date and it is highest for couple with one to two children, for families with younger and better educated PCGs and where no change in parents is observed.

\section{Economic vulnerability patterns and relative risk ratios}

In extending our analysis of the factors associated with patterns of vulnerability dynamics we conducted a multinomial (polytomous) logit regression on the pooled data for both cohorts. The dependent variable is the four-category 
indicator of economic vulnerability dynamics: vulnerable in neither period (the reference category); transient vulnerability (vulnerable in wave one only); becoming economically vulnerable (vulnerable in wave two only) and persistent vulnerability (vulnerable in both periods). The analysis uses weighted data with standard errors adjusted for clustering and weights. ${ }^{8}$ The results relating to relative risk ratios (RRRs) are set out in table 4 below. Goodness-of-fit statistics suitable for survey data estimators (i.e. when the svy prefix is used to ensure correct standard errors) are not available for multinomial regression models (StataCorp, 2013b). In the present context, since our focus is on model parameter estimates rather than comparing alternative models, the overall goodness of fit of the model is less critical. The adjusted Wald test is reported instead (Heeringa, West \& Berglund, 2010). This is a test of the null hypothesis that all parameters are not significantly different from zero. The test has a $p$ value less than .001 , indicating that the null hypothesis should be rejected.

The reference category for the dependent variable is being economically vulnerable in neither wave. The impact of socioeconomic factors is relatively uniform between the 2008 and 1998 cohorts. However, a number of significant variations emerge and these are taken into account by specific interaction terms. Focusing first on the relative risk of persistent vulnerability, by far the most significant influence is family type and in particular lone parenthood. Taking a couple with one child as the benchmark we find that the RRR for lone parents with two or more children reaches 74.8. For their counterparts with only one child the value falls to 22.4. There is then a sharp drop to 4.5 for a couple with three children and to 1.92 for those with two children. The next most important influence is educational level of the PCG. With third level as the reference category, the RRR for lower second level or below is 11.8 while for upper second and lower third level it is 2.9. Age of the PCG at birth of child has a significant but less substantial impact. With the 35-39 group as the benchmark, the RRR for the under 25 group was 3.6. (However, this value relates only to the 2008 cohort and falls to 2 for the 1998 cohort). It then fell to 1.8 for the 25-29 group and to 1.6 for the $40+$ group. No significant difference was observed for the 30-34 age group compared to the 35-39 age group. With the no change in parent(s) category as the reference group, the RRR for those where a parent died or left was 4.9. However, while a gross positive effect for the arrival of a new parent was observed, controlling for other factors leads to a net RRR of 0.6. In most cases, this pattern involved a formerly lone parent marrying, so that there was a shift from a one-parent to a two-parent family. The net effect of cohabitation was to raise the RRR by 1.7 and of more children to increase it by 1.5 .

Transient vulnerability is the pattern where the family was economically vulnerable in wave one but became non-vulnerable in wave two. Given the recession, this pattern was relatively unusual. Turning to a consideration of factors associated with this pattern, we find that taking a couple with one child as the benchmark, the RRR rises to 8.5 for lone parents with two or more children (However, for the 1998 cohort this increases to 20.1). For lone parents with one child the RRR is 5.2. There is no significant difference between couples with different numbers of children.

Age of PCG effects were similar to those for persistent poverty with the RRR ranging from 2.3 for the under 25 group to 1.9 for those aged 25-29 and no difference between families where the PCG was older at the birth of the child. Families where a parent subsequently left or died had an RRR of 2.6. In the 2008 cohort the arrival of a parent was associated with an RRR of 1.6 but for the 1998 cohort this fell to 0.7 with this group enjoying a relative advantage rather than a disadvantage. Cohabitation raises the RRR by 1.3 but families which subsequently had more children had an RRR of 0.7 . 
Table 4: Relative risk ratios for economic vulnerability dynamics for the 2008 and 1998 cohort (Reference category is vulnerable in neither period)

\begin{tabular}{|c|c|c|c|c|}
\hline & & \multicolumn{3}{|c|}{2008} \\
\hline & & $\begin{array}{l}\text { Transient } \\
\text { economic } \\
\text { vulnerability } \\
\text { (W1 only) }\end{array}$ & $\begin{array}{l}\text { Becoming } \\
\text { economically } \\
\text { vulnerable } \\
\text { (W2 only) }\end{array}$ & $\begin{array}{c}\text { Persistent } \\
\text { economic } \\
\text { vulnerability } \\
\text { (Both waves) }\end{array}$ \\
\hline Cohort (Ref: 2008 cohort) & 1998 cohort & 1.000 & 1.435 & 0.380 \\
\hline \multirow{4}{*}{$\begin{array}{l}\text { Age of PCG at birth of child } \\
\text { (35-39 ref.) }\end{array}$} & Under 25 & 2.292 & 3.644 & 3.606 \\
\hline & $25-29$ & 1.948 & 1.777 & 1.779 \\
\hline & $30-34$ & 1.000 & 1.000 & 1.000 \\
\hline & $40+$ & 1.000 & 1.553 & 1.576 \\
\hline \multirow{4}{*}{$\begin{array}{l}\text { Household Type W1 } \\
\text { (Ref: Couple, } 1 \text { child) }\end{array}$} & Lone parent, 1 child & 5.233 & 2.413 & 22.390 \\
\hline & Lone parent, $2+$ children & 8.460 & 4.266 & 74.830 \\
\hline & Couple, two children & 1.000 & 1.544 & 1.916 \\
\hline & Couple, $3+$ children & 1.000 & 2.778 & 4.483 \\
\hline Cohabiting W1? & Yes & 1.319 & 1.253 & 1.695 \\
\hline \multirow{2}{*}{$\begin{array}{l}\text { Change in parent(s) } \\
\text { (Ref: No change) }\end{array}$} & Yes & 1.619 & 1.000 & 0.567 \\
\hline & One parent died/left & 2.601 & 5.055 & 4.935 \\
\hline More children in Wave $2 ?$ & Yes & 0.693 & 1.262 & 1.504 \\
\hline \multirow{2}{*}{$\begin{array}{l}\text { PCG Education, W1 } \\
\text { (Ref: Upper 3rd) }\end{array}$} & Lower 2 nd or less & 5.215 & 4.498 & 11.800 \\
\hline & Upper 2nd to lower 3rd & 2.053 & 2.577 & 2.946 \\
\hline \multirow{5}{*}{$\begin{array}{l}\text { Age of PCG at birth of child } \\
\text { (Ref: } 35-39 \text { ) }\end{array}$} & & \multicolumn{3}{|c|}{1998 Cohort (where different) } \\
\hline & Under 25 & & 1.665 & 2.005 \\
\hline & $25-29$ & & 1.088 & \\
\hline & $30-34$ & & & \\
\hline & $40+$ & & & \\
\hline \multirow{4}{*}{$\begin{array}{l}\text { Household Type W1 } \\
\text { (Ref: Couple } 1 \text { child) }\end{array}$} & Lone parent, 1 child & & & \\
\hline & Lone parent, $2+$ children & 20.059 & & \\
\hline & Couple, two children & & & \\
\hline & Couple, $3+$ children & & 1.878 & \\
\hline Cohabiting W1? & Yes & & & \\
\hline \multirow{2}{*}{$\begin{array}{l}\text { Change in parent(s) } \\
\text { Ref: No change, same } \\
\text { parent(s)) }\end{array}$} & Yes & 0.661 & & \\
\hline & One parent died/left & & 3.084 & \\
\hline More children in Wave 2 ? & Yes & & & \\
\hline PCG Education, W1 & Lower 2 nd or less & 2.435 & & \\
\hline (Ref: Upper 3rd) & Upper 2nd to lower 3rd & 0.834 & 1.866 & \\
\hline
\end{tabular}

Source: GUI Longitudinal 1998 Cohort $(N=7,423)$ and 2008 Cohort $(N=9,793)$ datasets. Note: Where cell is blank for child cohort, relative risk ratio is the same as for 2008 cohort. Where Relative risk ratio is not statistically different from the reference category for the 2008 cohort at $p<=0.1,1.000$ is used in the table. Adjusted Wald test for all parameters: $F(55,10,298)=39.89 ; p$ value $<.001$.

A significant contrast between the 2008 and 1998 cohorts emerges in relation to the strength of the association between the educational level of the PCG and vulnerability in the first wave. For the 2008 cohort, lower secondary qualifications are associated with an RRR of 5.2 while for upper secondary to lower third level a value of 2.1 is observed compared to the reference category of PCGs with third level qualifications. For the PCGs of the 1998 cohort, where lower levels of qualifications were more the norm, the contrast by level of education is smaller and the respective values are 2.4 and 0.8 .

Becoming economically vulnerable (being vulnerable in wave two only) involves moving into vulnerability during the recession. Consistent with our earlier discussion of the gross effects, family type has a significantly weaker association with becoming economically vulnerable than with transient or persistent vulnerability. Taking a couple with one child as the reference category, the RRR for lone parents with two children is 4.3 while for 
those with one child it falls to 2.4. The RRR for a couple with three or more children is 2.8 while for those with two children it is 1.5. Thus lone parenthood plays a significantly weaker role for this outcome. For the 1998 cohort the only different effect is for a couple with three or more children where it falls to 1.9 compared to those with one child. Overall, family type is a much weaker factor in accounting for becoming economically vulnerable than for the other outcomes (persistent and transient vulnerability). In addition, the age of the PCG at the time the child was born has a stronger effect for the 2008 cohort than for the 1998 cohort. For the former the RRR for the 25 or under group is 3.6 and for the 25-29 category is 1.8 compared to the reference category of age 35-39. For the 1998 cohorts the respective figures are 1.7 and 1.1 . For both groups the RRR for the $40+$ group is 1.6 . For the 2008 cohort the impact of education is similar to that for transient vulnerability with RRRs of 4.5 and 2.6 but for the 1998 cohort the latter figure relating to higher second and lower third level falls to 1.9. Cohabitation and having more children raise the RRR modestly to 1.3 . In the 2008 cohort the departure or death of a parent increased the RRR of becoming economically vulnerable by 5.1 but for the 1998 cohort the RRR was lower at 3.1.

Controlling for all other variables in the model, the 1998 cohort was less likely to experience persistent vulnerability with an RRR of 0.4 but was more likely to be vulnerable in wave two only with an RRR of 1.4 .

Overall, our analysis indicates that the factors associated with risk of persistent vulnerability are somewhat different to those relating to transient vulnerability or becoming economically vulnerable.

\section{Conclusions}

In this paper we have sought to develop a multidimensional and dynamic approach to understanding the impact on families and children in Ireland of an unprecedented set of economic changes associated with the Great Recession.

The first and second waves of the Growing Up in Ireland survey spanned the period from the end of Ireland's economic boom through its entry into the Great Recession. Taking advantage of this timing we developed an approach to capturing multidimensional latent economic vulnerability of families, understood as involving a distinctive risk profile in relation to relative income, household joblessness and economic stress.

The recession was associated with a significant increase in levels of economic vulnerability and changing risk profiles for both the 2008 and 1998 cohorts. While the 2008 cohort displayed higher levels of persistent and transient vulnerability in the first wave, the transition into vulnerability in wave two was more evident for the 1998 cohort. This is consistent with the fact that the timing of the surveys meant that the first wave for the 1998 cohort took place before the start of the recession while the 2008 cohort was first approached after the recession had already begun. Economic stress levels increased for both vulnerable and nonvulnerable groups for both cohorts. The sharpest change in the vulnerability profile occurred for the 1998 cohort where the level of joblessness among the vulnerable decreased and they were significantly more widely distributed across the income distribution.

The factors affecting vulnerability outcomes were broadly similar for the 2008 and 1998 cohorts. Persistent economic vulnerability was significantly associated with lone parenthood, particularly for those with more than one child, lower levels of PCG education and, to lesser extent, younger age of PCG at child's birth, number of children and a parent leaving or dying. The vulnerability of lone parent and cohabiting families is consistent with other research in Ireland on the $1998 \mathrm{GUI}$ cohort (Fahey et al., 2012; Hannan \& Halpin, 2014). Results reported by Fahey et al. (2012) indicate that poverty and low levels of education are important in accounting for the lower wellbeing of children in one-parent families. Hannan and Halpin (2014), similarly, point to the significance of pre-existing differences, including socioeconomic differences between family types, in accounting for the disadvantage in health and self concept faced by children in lone parent or cohabiting families (Hannan \& Halpin, 2014).

The impact of educational qualifications points to the importance of continuing to emphasise education and skills acquisition, particularly for those at risk of early school leaving. In the more immediate term, the needs of lone parents outside the labour market need to be addressed. Because lone parent families have only one care giver, the challenge of balancing employment and child care is likely to be more acute. It is well established that 
interventions to improve the labour market skills of the unemployed bring benefits in terms of employment opportunities and future wages. What is less well understood is the mix of training, job search support and child care support that is needed to enhance the labour market prospects of lone parents. Further research is needed on the optimal mix of services and support needed to enhance the labour market prospects of lone parents as well as improving outcomes for their children.

Similar factors were associated with transient vulnerability but the magnitude of the effects was significantly weaker, particularly in relation to lone parenthood and level of education of the PCG. For entry into vulnerability the impact of these factors was again substantially weaker than for persistent and transient vulnerability indicating a significantly greater degree of socioeconomic heterogeneity among the group that became vulnerable during the recession. As a result, in the post-recession period the economically vulnerable became considerably more heterogeneous in terms of family type and educational level of the PCG. This is consistent with other research on financial stress among the adult population in Ireland which showed significant evidence of 'middle class squeeze', particularly at the middle stages of the life course (Maître, Russell and Whelan 2014; Whelan \& Maitre, 2014). The findings confirm the policy and political challenges presented by the scale of the Great Recession in Ireland which go well beyond catering for groups that traditionally have been characterised by a high dependence on social welfare. The substantially increased scale of economic vulnerability and the changing vulnerability profile in which subjective economic stress plays an increased role is consistent with evidence of the dramatic increase in household indebtedness in Ireland (Russell et al., 2013). Dealing with the political pressures arising from the broad range of households who have been affected by unprecedented economic circumstances presents formidable challenges to a welfare state which has traditionally emphasised targeted provision of limited means-tested benefits for only the most economically vulnerable groups.

\section{Acknowledgements}

We would like to thank Richard Layte and two anonymous readers for constructive comments on an earlier version of this paper. Growing Up in Ireland data have been funded by the Government of Ireland through the Department of Children and Youth Affairs; and have been collected under the Statistics Act, 1993, of the Central Statistics Office. The project has been designed and implemented by the joint Economic and Social Research Institute - Trinity College Dublin Growing Up in Ireland Study Team.

\section{References}

Bradshaw,J., Hoelscher,P. \& Richardson, D. (2006). Comparing Child Well-Being in OECD Counties: Concepts and Methods. Florence: UNICEF Innocenti Research Centre. Innocento Working Paper IWP-2006-03

Bradshaw, J. \& Main, G. (2010). PSE Measures Review Paper: Children's Deprivation Items (Poverty and Social Exclusion in the UK: The 2011 Survey, Working Paper Series; No. 7). [s.I.] Poverty and Social Exclusion.

Bradshaw, J. \& Richardson, D. (2009). An Index of Child Well-Being in Europe, Child Indicators Research, 2,3, 319-51 http://dx.doi.org/10.1007/s12187-009-9037-7

Callan, T., Nolan, B., Keane, C., Savage, M \& Walsh, J. R. (2013). Crisis, response and distributional impact: the case of Ireland. IZA Journal of European Labour Studies, 3,9, 1-17

Duncan, G.J., Magnuson, K., Kalil, A. \& Ziol-Guest, K. (2012). The Importance of Early Childhood Poverty, Social Indicators Research, 108, 87-98. http://dx.doi.org/10.1007/s11205-011-9867-9

Fahey, T., Keilthy, P. \& Polek, E. (2012). Family Relationships and Family Well-Being: A Study of the Families of Nine Year Olds in Ireland. Dublin: Family Support Agency. 
Grusky, D.B. \& Weeden, K.A. (2007). Measuring Poverty: The Case for a Sociological Approach, in Kakawani, N. \& Silber, J. (eds) The Many Dimensions of Poverty. Basingstoke, UK: Palgrave Macmillan.

Hannan, C., \& Halpin, B. (2014). The Influence of Family Structure on Child Outcomes: Evidence for Ireland. Economic and Social Review, 45, 1-24.

Heeringa, S. G., West, B. T. \& Berglund, P. A. (2010). Applied Survey Data Analysis, 273-275. Boca Raton, FL: Chapman \& Hall/CRC.

Hanappi, D., Bernardi, L. \& Spini, D. (2015). Vulnerability as a heuristic concept for interdisciplinary research: assessing the thematic and methodological structure of empirical lifecourse studies, Longitudinal and Life Course Studies, 6, 1, 59-97.

http://dx.doi.org/10.14301/llcs.v6i1.302

IMF. (2003). Vulnerability Indicators: A Factsheet. Washington, DC: International Monetary Fund. http://www.imf.org/external/np/exr/facts/vul.htm

Lazarsfeld, P. F., (1950). The Logical and Mathematical Foundation of Latent Structure Analysis, in S. Stouffer, L. Guttman, E. Suchman, P. Lazarsfeld, S. Star, S. \& J. Clausen. (Eds.), Measurement and Prediction, Princeton, NJ: Princeton University Press.

Maitre, B., Russell, H. \& Whelan, C. T. (2014) Trends in Economic Stress and the Great Recession in Ireland: An Analysis of the CSO Survey on Income and Living Conditions (SILC). Dublin: Department of Social Protection.

McCutheoen, A. \& Mills, C. (1998). Categorical Data Analysis; Log-Linear and Latent Class Models, in E. Scarborough \& E. Tannenbauum (Eds.), Research Strategies in the Social Sciences, Oxford: Oxford University Press.

http://dx.doi.org/10.1093/0198292376.003.0005

Moisio, P. (2004). A latent class application to the multidimensional measurement of poverty, Quantity and Quality-International Journal of Methodology 38 (6), 703-17. http://dx.doi.org/10.1007/s11135-004-5940-7

Mood, C. \& Jonsson, J. (2014). Poverty and Welfare among children and their families 1968-2010, Institute for Future Studies, Research Report 2014/2, Stockholm.

Murray, A., McCrory, C., Thornton, M., Williams, J., Quail, A., Swords, L., Doyle, E. \& Harris, E. (2010). Growing Up in Ireland, National Longitudinal Study of Children: Design, Instrumentation and Procedures for the Child Cohort. Dublin: Department of Health and Children.

Nolan, B. \& Whelan, C. T. (1996). Resources, Deprivation and Poverty, Oxford: Oxford University Press.

Nolan, B. \& Whelan, C T. (2007). On the multidimensionality of poverty and social exclusion, In Micklewright, J., Jenkins, S. (Eds.), Poverty and Inequality: New Directions. Oxford University Press, Oxford.

Nolan, B. \& Whelan, C T. (2010). Using Non-Monetary Deprivation Indicators to Analyse Poverty and Social Exclusion in Rich Counties: Lessons from Europe? Journal of Policy Analysis and Management, 29,2, 305-323. http://dx.doi.org/10.1002/pam.20493

Russell, H., Whelan, C, T. \& Maître, B (2013). Economic Vulnerability and Severity of Debt Problems: An Analysis of the Irish EU-SILC 2008

StataCorp (2013a). Stata: Release 13. Statistical Software. College Station, TX: StataCorp LP.

StataCorp (2013b). Stata Survey Data Reference Manual, Release 13. College Station, TX: StataCorp LP.

Thornton, M., Williams, J., McCrory, C., Murray, A. \& Quail, A. (2013). Growing Up in Ireland, National Longitudinal Study of Children: Design, Instrumentation and Procedures for the Infant Cohort at Wave 1 (9 months). Dublin: Department of Health and Children.

Tomlinson, Walker, R., \& Williams, G. (2009), Measuring Poverty in Britain as a Multidimensional Concept, 1991 to 2003, Journal of Social Policy, 37, 4: 597-620

UNICEF (2007), Child Poverty in Perspective: An overview of child well-being in rich countries. A comprehensive assessment of the lives and well-being of children and adolescents in the economically advanced nations, Florence: UNICEF Innocenti Research Centre, Innocenti Report Card 7 
UNICEF (2014), Children of the Recession: the impact of the economic crisis on the the well-being of children, UNICEF Innocenti Research Centre, Innocenti Report Card 12

UNITED NATIONS (2003). Report on the World Social Situation: Social Vulnerability: Sources and Challenges. New York: United Nations Department of Economic and Social Affairs

Watson, D., Maître, B. \& Whelan, C.T. (2012), Understanding Childhood Deprivation in Ireland. Dublin: Department of Social Protection

Whelan, C.T \& Maître, B. (2005) Vulnerability and Multiple Deprivation: Perspectives on Economic Exclusion in Europe: A Latent Class Analysis, European Societies 7(3),423-50

Whelan, C. T. \& Maître, B (2010), Welfare Regime and Social Class Variation in Poverty and Economic Vulnerability, Journal of European Social Policy, 20, 4, 3, 316-332

Whelan, C. T. \& Maître, B. (2014), The Great Recession and the Changing Distribution of Economic Vulnerability by Social Class: The Irish Case, Journal of European Social Policy, 24, 5, 470-485. http://dx.doi.org/10.1177/0958928714545444

Whelan, K. (2010) Policy Lessons for Ireland's Latest Depression, Economic and Social Review, 41 (2), 225-54. World Bank. (2000). World Development Report 2000-01: Attacking Poverty, New York: Oxford University Press.

\section{Endnotes}

${ }^{1}$ The recent UNICEF (2014) report on child poverty calculated changes in poverty rates using a poverty line fixed at $60 \%$ of median income in 2008 and adjusting the 2012 line for inflation. Given the scale of the recession in Ireland, it is not surprising that it fares particularly badly on such 'peak to trough' indicators, which fail to take into account the substantial increase in household incomes during the boom, in contrast with the outcome employing conventional income poverty measures.

${ }^{2}$ For a discussion of design and reweighting procedures for both cohorts, see Murray et al, 2010 and Thornton et al, 2013.

${ }^{3}$ For a recent discussion of the use of vulnerability as a heuristic concept see Hanappi et al., (2014).

${ }^{4}$ The scale assigns a weight of 1 to the first adult in a household, a weight of 0.66 to each additional adult and of 0.33 to children. The equivalised household income is thus calculated as the total household net income divided by the number of equivalent adults in the household.

${ }^{5}$ Nevertheless, the median equivalised household incomes as measured in the GUI are very similar to the figures obtained in the SILC surveys for the comparable years and for families of children in the same age groups.

${ }^{6}$ Extending the analysis to allow for a larger number of latent classes would require increasing the number of categories in our indicators in order to have sufficient degrees of freedom to conduct the analysis and would lead to a significantly less parsimonious account of economic differentiation.

${ }^{7}$ The class sizes based on modal allocation are lower than the estimated sizes of the vulnerable classes, at $27 \%$ for the nine-month olds, $30 \%$ for the three-year olds, $19 \%$ for the nine-year olds and $30 \%$ for the 13 year olds. However, the pattern across cohorts and over time is very similar.

${ }^{8}$ This was accomplished using the 'svy' routine in Stata (StataCorp, 2013b). The data are in 'wide' format, so there is one case per child. The 1998 cohort is clustered at school level. Clustering has implications for the standard errors and significance tests but not for the sizes of coefficients (Heeringa et al., 2010). There is no clustering in the 2008 cohort but adjusted standard errors are still required to take account of the weights. 